УДК 539.421.2

\title{
ВЛИЯНИЕ КОНЦЕНТРАТОРОВ НАПРЯЖЕНИЙ НА УСТАЛОСТНУЮ ПРОЧНОСТЬ ТРУБОПРОВОДА
}

Исламов Алим Азатович

студент

Научный руководитель: Гарифуллина Гульназ Ильфировна

к.т.н., преподаватель

ГАПОУ «Туймазинский индустриальный колледж»

\begin{abstract}
Аннотация: большое количество трубопроводов, машин и аппаратов нефтегазовой отрасли в процессе эксплуатации подвергается воздействию циклически изменяющихся нагрузок. Это приводит к развитию усталостных повреждений. Примерно 90\% повреждений деталей связано с возникновением и развитием усталостных трещин. Поэтому актуальной и важной задачей является оценка опасности обнаруженных дефектов.

Ключевые слова: усталость металла, циклические нагрузки, концентраторы напряжений, теоретический коэффициент концентрации напряжений, предел текучести стали.
\end{abstract}

\section{INFLUENCE OF VOLTAGE CONCENTRATORS ON THE FATIGUE STRENGTH OF THE PIPELINE}

\section{Islamov Alim Azatovich Scientific adviser: Garifullina Gulnaz Ilfirovna}

\begin{abstract}
A large number of pipelines, machines and apparatuses of the oil and gas industry are exposed to cyclically varying loads during operation. This leads to the development of fatigue damage. Approximately $90 \%$ of the damage to parts is due to the occurrence and development of fatigue cracks. Therefore, an urgent and important task is to assess the risk of detected defects.

Key words: metal fatigue, cyclic loads, stress concentrators, theoretical stress concentration coefficient, yield strength of steel.
\end{abstract}


На всех этапах развития техники усталость металлов всегда считалась одной из главных причин аварийных разрушений и отказов оборудования различного назначения. Многие отказы производственных объектов вызваны усталостными явлениями (нефте- и газопроводы, аппараты химических производств, резервуары, самолеты и т.д.). Примерно 90\% повреждений деталей связано с возникновением и развитием усталостных трещин. Поэтому актуальной и важной задачей является оценка опасности обнаруженных дефектов.

Усталость металла - это процесс постепенного накопления повреждений под действием переменных напряжений (деформаций), приводящих к изменению свойств, образованию трещин и разрушению [4, с. 15].

Усталостные трещины имеют жесткую привязку к концентраторам напряжений. Особенностью работы металла трубопровода является наличие надрезов, рисок, царапин, задиров, вмятин на его поверхности. Кроме того, в процессе эксплуатации развиваются коррозионные язвы на поверхности трубы. Сварные швы также являются концентраторами напряжений [3, с.156].

Усталостные трещины возникают при повторно-переменных нагрузках. Циклические деформации в металле трубопровода возникают за счет изменения давлений и температуры перекачиваемого продукта, особенностей технологического процесса. Внутреннее давление нередко падает из-за сбоев, аварий, переключений насосов, в результате чего трубопровод работает в условиях перепада нагрузок. Трещины усталости создают предпосылки для хрупкого разрушения, и в этом одна из главных причин их опасности [2, с. 80].

Для описания уровня концентрации напряжений в дефектах введено понятие теоретического коэффициента концентрации напряжений:

$$
\alpha=\frac{\sigma_{\max }}{\sigma_{n}},
$$

где $\sigma_{\max }$ - максимальное напряжения в зоне концентрации напряжений,

$\sigma_{\mathrm{n}}-$ номинальное напряжение при упругой деформации.

В качестве исследуемого объекта рассматривался трубопровод 159х6мм узла фильтра нефтепродуктов (рисунок 1). Материал трубы сталь марки ВСт3сп. Предел текучести стали $\sigma_{\mathrm{T}}=205 \mathrm{MПа}$, допускаемое напряжение $[\sigma]=154 \mathrm{MПа}$. 


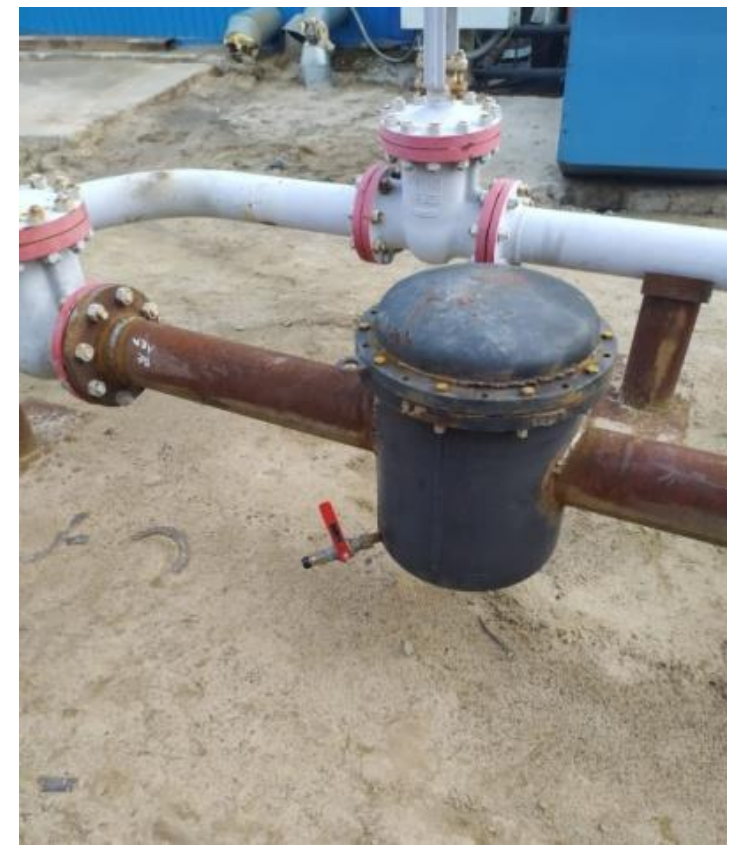

\section{Рис. 1. Узел фильтра нефтепродуктов}

На трубопроводе имелись концентраторы напряжений: сварные швы, механические риски, царапины, надрезы, коррозионные язвы, дефекты в виде округлой поры в сварном шве. Геометрические размеры концентраторов напряжений приведены на рисунке 2.
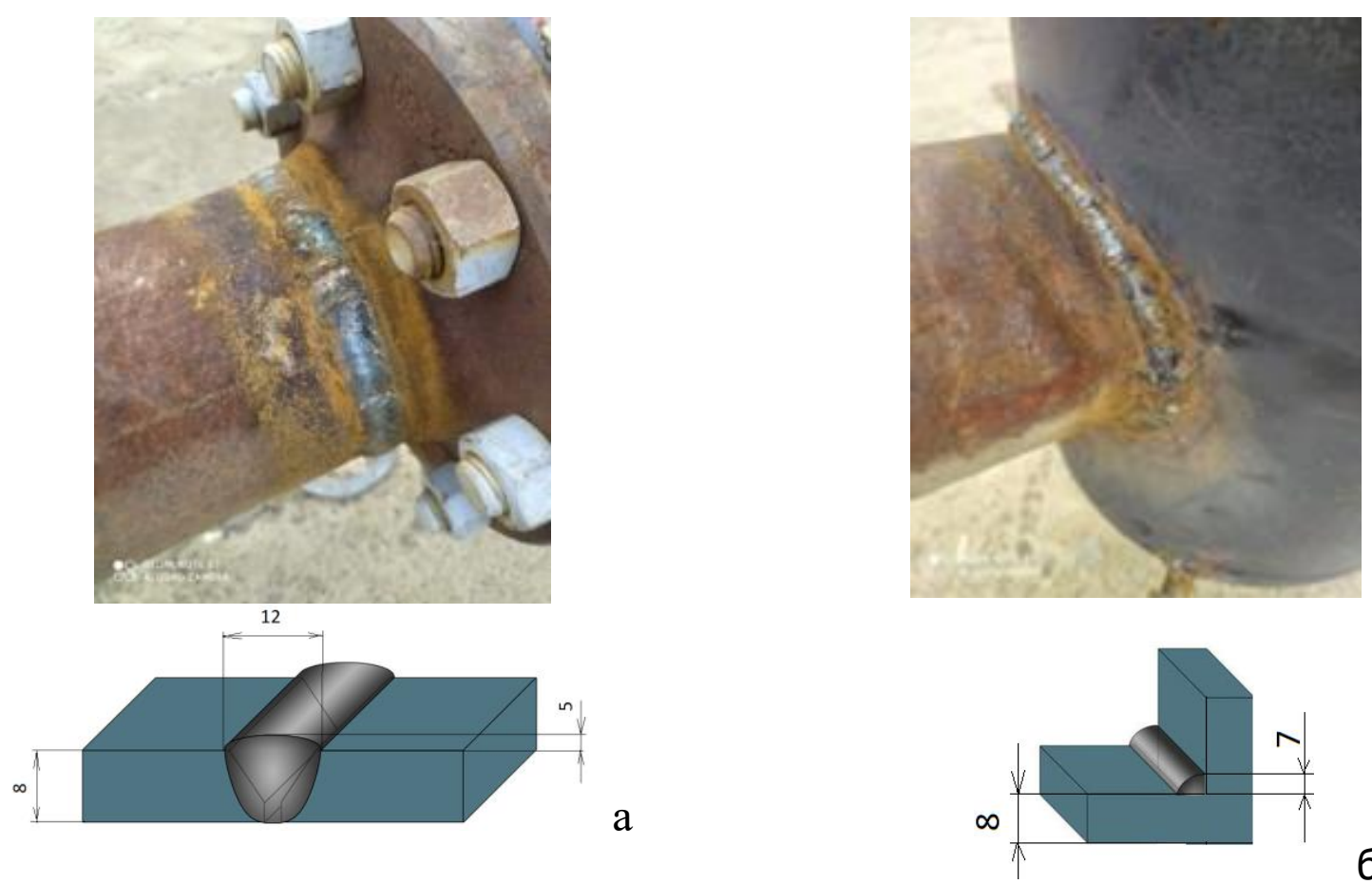


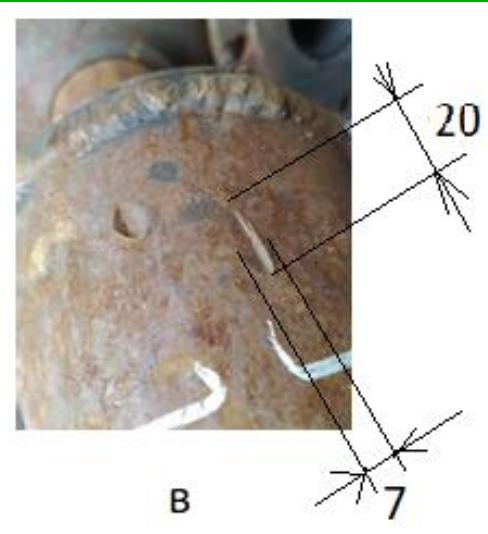

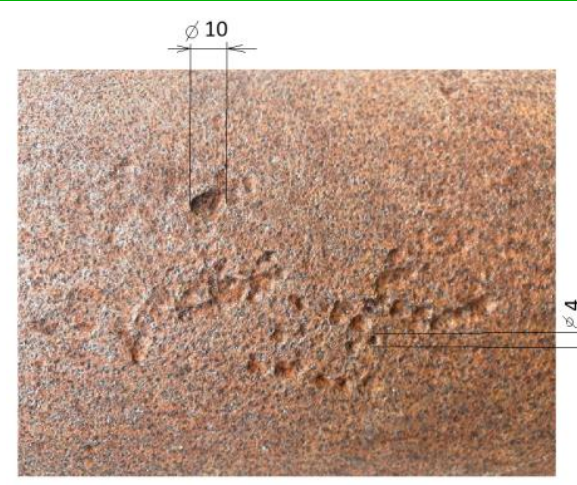

$\Gamma$

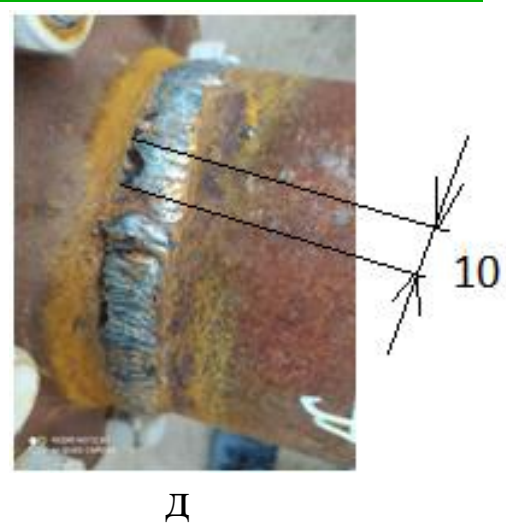

Д

\section{Рис. 2. Геометрические параметры концентраторов напряжений:}

а - сварной шов (С56); б - сварной шов (У17);

в - механические риски, царапины, надрезы; г - коррозионная язва, д - дефект в виде округлой поры в сварном шве

Для стыкового соединения теоретический коэффициент концентрации напряжений рассчитывается по формуле В. А. Кархина [2, с. 82]:

$$
\alpha_{\sigma}=1+\frac{1}{\sqrt{\rho \cdot\left(\frac{14}{b}+\frac{1.7}{c}+\frac{5}{\delta}\right)}}=1+\frac{1}{\sqrt{15 \cdot\left(\frac{14}{12}+\frac{1,7}{2}+\frac{5}{6}\right)}}=1
$$

где $\rho$ - радиус перехода от шва к основному металлу, мм; $b$ - ширина шва, мм; с - высота усиления шва, мм; $\delta$ - толщина металла, мм.

В тавровых, нахлесточных, угловых соединениях теоретический коэффициент концентрации напряжений рассчитывается по формуле Г.П.Турмова:

$$
\alpha_{\sigma}=1+0,2 \cdot \sqrt{\frac{2 \cdot \delta-K}{\rho}}=1+0,2 \cdot \sqrt{\frac{2 \cdot 6-7}{15}}=1,2,
$$

где К - катет шва, мм.

Теоретический коэффициент концентрации напряжений для коротких механических рисок, царапин, надрезов и задиров при условии, что $\mathrm{d}<1<10 \mathrm{~d}$, рассчитывается по формуле [1, с.53]:

$$
\begin{gathered}
\alpha_{\sigma}=1+3,57 \cdot \frac{b}{d} \cdot \frac{1,12-0,96 \cdot \frac{b}{l}}{1-b / \delta \cdot(1-1,5 \cdot b / l)}= \\
=1+3,57 \cdot \frac{4}{7} \cdot \frac{1,12-0,96 \cdot \frac{4}{20}}{1-4 / 8 \cdot\left(1-1,5 \cdot \frac{4}{20}\right)}=3,9,
\end{gathered}
$$

где $\delta$ - толщина трубы, мм; 1 - длина дефекта, мм; d - ширина дефекта, мм; b - глубина дефекта, мм. 
При наличии коррозионной язвы на поверхности трубопровода теоретический коэффициент концентрации напряжений рассчитывается по формуле:

$$
\begin{gathered}
\alpha_{\sigma}=1+3,57 \cdot \frac{b}{d} \cdot \frac{1,12-0,96 \cdot(b / d)}{1-(b / d) \cdot(1-1,5 \cdot b / d)}= \\
=1+3,57 \cdot \frac{5}{10} \cdot \frac{1,12-0,96 \cdot(5 / 10)}{1-(5 / 10) \cdot(1-1,5 \cdot 5 / 10)}=2,3,
\end{gathered}
$$

где d - диаметр язвы, мм; b - глубина язвы, мм.

При наличии округлой поры в сварном шве для расчета теоретического коэффициента концентрации напряжений используется следующая формула:

$$
\alpha_{\text {пор }}=1+\frac{1,28}{1-\frac{d}{\delta} \cdot 0,25}=1+\frac{1,28}{1-\frac{10}{6} \cdot 0,25}=3,2,
$$

где d - диаметр поры, мм; $\delta$ - толщина стенки трубы, мм.

Таким образом, наиболее опасными концентраторами напряжений являются механические риски, царапины, надрезы $\left(\alpha_{\sigma}=3,9\right)$. Наличие дефектов в сварном шве также существенно увеличивают концентрацию напряжений $\left(\alpha_{\text {пор }}=3,2\right)$. В коррозионной язве коэффициент концентраций напряжений достигает 2,3.

В процессе эксплуатации трубопровод узла фильтра работает под давлением 40 атм (4МПа). Напряжение в теле трубы определим по формуле Барлоу:

$$
\sigma=\frac{p \cdot d}{2 \cdot \delta}=\frac{4 \cdot 159}{2 \cdot 6}=53 \mathrm{M \Pi а},
$$

где $\mathrm{p}$ - давление в трубе, МПа; $\mathrm{d}$ - диаметр трубы, мм; $\delta$ - толщина стенки трубы, мм.

Величина напряжений в обнаруженных дефектах представлена в таблице1.

Таблица 1

\section{Значения напряжений в сварных швах и дефектах трубы}

\begin{tabular}{|l|c|c|c|c|c|}
\hline $\begin{array}{l}\text { капня- } \\
\text { жентя }\end{array}$ & $\begin{array}{c}\text { сварной } \\
\text { шов С56 }\end{array}$ & $\begin{array}{c}\text { сварной шов } \\
\text { У17 }\end{array}$ & $\begin{array}{c}\text { механические } \\
\text { риски, } \\
\text { царапины }\end{array}$ & $\begin{array}{c}\text { коррозионная } \\
\text { язва }\end{array}$ & $\begin{array}{c}\text { поры в } \\
\text { сварном } \\
\text { шве }\end{array}$ \\
\hline $\begin{array}{l}\text { напряжения } \sigma, \\
\text { МПа }\end{array}$ & $\begin{array}{c}53 \cdot 1,2= \\
63,6 \mathrm{MПа}\end{array}$ & $\begin{array}{c}53 \cdot 1,2= \\
63,6 \mathrm{M} \text { Па }\end{array}$ & $\begin{array}{c}53 \cdot 3,9= \\
206,7 \mathrm{M} П а\end{array}$ & $53 \cdot 2,3=121,9 \mathrm{MПа}$ & $\begin{array}{c}53 \cdot 3,3= \\
174,9 \mathrm{M} \text { Па }\end{array}$ \\
\hline
\end{tabular}

Напряжения в механических рисках, царапинах, надрезах и в сварном шве с дефектом в виде округлой поры существенно превышают допускаемое напряжение для стали ВСтЗсп. Кроме того, напряжения в механических 
дефектах превышают предел текучести стали. Следовательно, концентратор напряжений будет работать в области пластических деформаций, что приведет к возникновению и развитию усталостных трещин.

C целью уменьшения концентрации напряжений рекомендуется устранить механические дефекты, также исключить поры в сварных швах.

\section{Список литературы}

1. ОСТ 153-39.4-010-2002 Методика определения остаточного ресурса нефтегазопромысловых трубопроводов и трубопроводов головных сооружений: утвержден и введен в действие приказом Минэнерго России от 5 августа 2002г., N255: дата введения 2002-10-01. - URL https://docs.cntd.ru/document/1200032590 (дата обращения: 29.04.2021). - Текст: электронный.

2. Гареев А.Г., Худяков М.А., Абдуллин И.Г. Разрушение материалов в коррозионных средах: учеб. пособие. - Уфа: Изд-во УГНТУ, 2004. - 124 с.

3. Степнов М.Н., Зинин А.В. Прогнозирование характеристик сопротивления усталости материалов и элементов конструкций. - М.: Изд-во Инновационное машиностроение, 2016. - 392 с.

4. Терентьев В.Ф, Кораблева С.А. Усталость металлов. - М.: Наука, 2015. $-484 \mathrm{c}$.

(C) А.А. Исламов, 2021 